\title{
Literatura surda: representações em produções editoriais
}

\section{Resumo}

Universidade Federal do Rio Grande do Sul

Na articulação aos Estudos Culturais em Educação e aos Estudos Surdos, objetiva-se analisar representações surdas em produções editoriais de surdos, de diferentes gêneros textuais de caráter autobiográfico (narrativas de vida, poemas, crônicas e romances). Essas obras circulam em português escrito e compõem a literatura surda. Opera-se principalmente com o conceito de representação (HALL, 1997), compreendendo a linguagem como produtora de significados. Nas onze (1 1 ) obras discursivamente analisadas neste artigo, as quais foram escritas por surdos e são destinadas ao público-leitor juvenil e adulto, observamos a busca pela desconstrução de estereótipos atribuídos aos surdos. Além disso, os autores dos livros produzem autorrepresentações positivas, legitimadas através de seus exitosos exemplos de vida e de paratextos que integram as produções editoriais. Diante das lutas e de movimentos das comunidades surdas, além das políticas públicas de incentivo à cultura, os escritos surdos têm conquistado territórios culturais, expandindo o mercado editorial que tematiza narrativas sobre sujeitos considerados 'diferentes'.

Palavras-chave: Surdos. Literatura surda. Representação.

\section{Deaf literature: representations in editorial productions}

\section{Abstract}

In conjunction to Cultural Studies in Education and Deaf Studies, we aim to analyze deaf representations in editorial productions of deaf people, of different genres of autobiographical character (life narratives, poems, essays and novels). These books circulate in writing Portuguese and compose the deaf literature. It operates mainly with the concept of representation (Hall, 1997), including language as a producer of meanings. In the eleven (11) discursively works analyzed in this article, which was written by deaf persons and are intended for youth and adult readership, there is the search for deconstructing stereotypes attributed to the deaf persons. Moreover, the authors of the books produce positive self-representations, legitimized by its successful examples of life and paratexts that integrate editorial productions. Faced with the struggles and movements of deaf people's communities and public policies to encourage culture, the deaf writings have conquered cultural territories, expanding the publishing market that thematizes narratives about subjects considered 'different'.

Keywords: Deaf. Deaf literature. Representation. 


\section{Literatura sorda: representaciones y editores productions}

\section{Resumen}

En conjunción con los Estudios Culturales en Educación e a los Estudios de Sordos, se intentó evaluar las representaciones sordas en los editoriales de producciones de las personas sordas, de diferentes géneros de carácter autobiográfico (narrativas de vida, poemas, ensayos y novelas). Estas obras circulan en portugués escrito y componen la literatura sorda. Operamos principalmente con el concepto de representación (Hall, 1997), comprendiendo el idioma como productor de significados. En las once (1 1 ) obras discursivamente analizadas en este artículo, que fueram escritas por personas sordas y están destinadas a jóvenes y adultos lectores, observamos la búsqueda de la deconstrucción de los estereotipos atribuidos a los sordos. Por otra parte, los autores de los libros producen auto-representaciones positivos, legitimados por sus ejemplos exitosos de vida y de paratextos que integran las producciones editoriales. Frente a las luchas y los movimientos de las comunidades sordas y las políticas públicas para fomentar la cultura, los escritos sordos han conquistado territorios culturales, ampliando el mercado editorial que tematiza narrativas sobre temas considerados "diferentes".

Palabras clave: Sordo. La literatura sorda. Representación.

\section{Situando o trabalho}

Uma narrativa acontece em um mundo de narrativas não demarcadas por um início ou fim, que são construídas a partir da intertextualidade: cada livro é constituído na relação com outros livros; nossas histórias se dão por meio de outras, às quais temos acesso, ou que constituímos quando nos narramos.

Além disso, uma narrativa, por fragmentária que seja, a partir de princípios, "[...] compõe um modelo do real, faz um recorte do mundo e ameniza a ameaça da Esfinge: decifra-me ou te devoro" (CADEMARTORI, 2009, p. 49). Ainda segundo a autora, contar é um modo de refletir sobre os acontecimentos narrados, pois quem conta é a voz narrativa, aquela que, dirigindo-se ao leitor, The apresenta o mundo criado. Também o faz segundo um ponto de vista, a partir do qual é percebida a experiência da personagem.

As narrativas, por mais simples que sejam, buscam atender a expectativas dos leitores, manifestando interpretações de fatos e de fenômenos, principalmente humanos. Nesses processos, constituídos pelas palavras, são produzidos sentidos e criadas verdades que funcionam como mecanismos 
de subjetivação. Em tempos de "[...] empréstimos e negociações entre várias línguas, entre línguas e imagens, não captamos os significados se não observarmos as peripécias das palavras, o modo como deslizam pelas ações daqueles que leem [...]" (CANCLINI, 2008, p. 13). Os vocábulos não estão 'soltos no ar'; são encontrados a partir da forma como os vemos, ou seja, dos enunciados que nos constituem e daqueles que produzimos para entendermos o mundo.

Nomear o que fazemos, em educação ou em qualquer outro lugar, como técnica aplicada, como práxis reflexiva ou como experiência dotada de sentido, não é somente uma questão terminológica. As palavras com que nomeamos o que somos, o que fazemos, o que pensamos, o que percebemos ou o que sentimos são mais do que simplesmente palavras. E, por isso, as lutas pelas palavras, pelo significado e pelo controle das palavras, pela imposição de certas palavras e pelo silenciamento ou desativação de outras palavras são lutas em que se joga mais do que simplesmente palavras, mais que somente palavras (LARROSA, 2015, p. 18).

As palavras também se fazem presentes em representações que cada cultura passa a fazer de si e dos outros, como uma forma de dar sentido às suas próprias experiências e tradições, constituindo modos de ser e de viver. Os significados são produzidos, partilhados e negociados pela linguagem nas interações pessoais e sociais, pela variedade de meios (impressos ou tecnológicos, por exemplo), quando nos apropriamos de algumas verdades e tecemos narrativas. $\bigcirc$ significado é construído pelo trabalho da representação e surge em relação aos diferentes momentos ou práticas do circuito da cultura, isto é, na construção da identidade, na delimitação da diferença, na produção e no consumo da cultura, bem como na regulação das condutas sociais (HALL, 1997).

Nesses processos de representação - produção de significados através da linguagem -, os discursos não são apenas entendidos como conjunto de signos que representam, mas "[...] como práticas que formam sistematicamente os objetos de que falam" (FOUCAULT, 2005, p. 55). Ainda na perspectiva foucaultiana, percebemos que as práticas discursivas são reguladas por uma série de regras e de procedimentos sobre quem fala, de onde e para quem fala. Além disso, o "[...] discurso não é simplesmente aquilo que traduz as lutas ou 
os sistemas de dominação, mas aquilo por que, pelo que se luta, o poder do qual nos queremos apoderar" (FOUCAULT, 2014, p. 10).

É a linguagem que permite a criação de um sistema de significações para representar coisas e negociar sentidos sobre elas. É sobre os sentidos que damos às coisas que construímos nossas experiências cotidianas e nossas interpretações sobre nós e os outros. Se a linguagem nos permite entrar em um campo social de produção de verdades e de representações, ela também nos permite inventar a surdez de muitas formas, dependendo das relações em que estamos mergulhados (LOPES, 2010, s/p).

Pensando desse modo, problematizamos esses processos de significação culturalmente construídos, principalmente a partir da análise discursiva. Para isso, na perspectiva foucaultiana, voltamo-nos a produções editoriais surdas, aqui entendidas como artefatos da cultura surda. Mesmo diante de um processo de afirmação cultural, a cultura surda não se constitui como homogeneizada, cristalizada, de pureza essencial, pois cada sujeito surdo constrói sua identidade e representa a si mesmo a partir de suas experiências; a cultura surda desloca-se, fragiliza-se e se hibridiza no contato com outras culturas.

Assim, compreendemos a surdez "[...] como um território de lutas, um espaço de conflitos de identidades, onde os elementos culturais circulam pelas fissuras e rachaduras dessa comunidade, conformando um labirinto de significados" (KLEIN; LUNARDI, 2006, p. 15). A negociação sobre a surdez, o 'ser surdo' e sua cultura dá-se por meio da linguagem, no interior das relações de poder.

Nessa esteira de pensamento, os surdos, "[...] entendidos como povo ou grupo que se nomeia como tal, estão inscritos na ordem do acontecimento cultural, ou seja, na ordem da luta permanente do tornar-se, do vir a ser, frente a outro(s) grupo(s)" (LOPES; VEIGA-NETO, 2010, p. 127-128). O 'ser surdo' é aqui entendido como "[...] um sujeito possuidor de uma língua, de uma cultura e de identidades múltiplas, um sujeito social e politicamente construído, diferente" (MORAIS; LUNARDI-LAZZARIN, 2009, p. 25). Falar de surdo é também pensá-lo como sujeito plural, multifacetado, cuja experiência de ser, de estar no mundo, que é coletiva no encontro com outros surdos, é sentida de maneiras singulares; trata-se de uma experiência que nos surdos deixa sinais que formam a sua condição surda de viver. 
Na articulação ao campo dos Estudos Culturais em Educação, mais precisamente aos Estudos Surdos, este artigo objetiva analisar representações surdas em produções editoriais de surdos, de diferentes gêneros textuais de caráter autobiográfico (narrativas de vida, poemas, crônicas e romances). Essas obras circulam em português escrito e compõem a literatura surda. A análise dessas produç̃ões, destinadas ao público juvenil e adulto, possibilita notar uma conversão significativa no processo de representação surda: na tentativa de desconstruir estereótipos atribuídos aos surdos, os autores dos livros buscam uma autorrepresentação positiva, legitimada através dos exemplos próprios de vida e de paratextos que integram as obras publicadas.

Essa afirmação é sustentada pela materialidade discursiva-investigativa deste trabalho, constituída por onze (1 1 ) obras publicadas e que circulam no mercado editorial brasileiro: O Som das palavras: antologia literária, com produções de vários surdos; No meu silêncio ouvi e vivi, de Olindina Coelho Possídio; O Voo da Gaivota, de Emmanuelle Laborit; Despertar do Silêncio e Recortes de uma vida: descobrindo o amanhã, de Shirley Vilhalva; Como é ser surdo, de Vera Strnadová; A juventude, o carnaval e o Rio de Janeiro, de Celso Badin; Mãos ao vento, de Sylvia Lia Grespan Neves; Meus Sentimentos em Folhas, de Ronise Oliveira; Bela do silêncio, de Brenda Costa; e A verdadeira beleza: uma história de superação, de Vanessa Vidal.

Com exceção das obras da francesa Emmanuelle Laborit e da theca Vera Strnadová, que circulam no Brasil a partir de edições traduzidas, respectivamente da modalidade escrita do francês e theco para o português, as demais produções são de surdos brasileiros. Nas obras analisadas, a escrita em segunda língua é desenvolvida pela autoria, escrita colaborativa, ou pela tradução de Libras para português. Essas produções compõem o que entendemos por literatura surda, como aprofundamos na próxima seção deste texto.

\section{Produções editoriais na literatura surda}

Tradicionalmente, em processos de construção de significados sociais, a literatura tem sido remetida à noção de cânone, como escrita autorizada e priorizada por uma minoria influente; ou seja, sob influência de padrões acadêmicos, as produções ainda têm sido definidas como literatura, ou não, de acordo com a sua qualidade de escrita e possibilidade de se tornarem clássicas. Tambling, citado por Hunt (2010), assume que algumas obras são lidas 
como literárias porque há escritores que configuram um padrão imaginário, isto é, a obra torna-se literária pela relação que é estabelecida com o autor de produção de status já reconhecido.

Nesse sentido, os livros escritos por surdos, em análise neste texto, têm sido reconhecidos e valorizados na cultura surda, produzidos por líderes em comunidades surdas e/ou sujeitos bem-sucedidos na sociedade. Na capa da obra Recortes de uma vida: descobrindo o amanhã, afirma-se que - livro contempla o "[...] depoimento de uma professora surda parcial, que recebeu Medalha Educação BPW CG2000 do Projeto $\bigcirc$ mestre que marcou minha vida". Acerca da escritora Brenda Costa, na contracapa de sua obra autobiográfica, lê-se: "Guerreira e vencedora, hoje Brenda Costa é top model internacional". Outro exemplo de status atribuído aos autores surdos encontra-se na obra de Sylvia Lia Grespan Neves, apresentada como pedagoga surda, graduanda em Letras-Libras (UFSC), docente de Língua Brasileira de Sinais (Libras) em cursos de graduação e de pós-graduação.

Como o mercado editorial abriu portas para textos de caráter autobiográfico, que, por sua vez, têm um público consumidor, essas produções podem ser entendidas como literárias. Caracterizada como um conjunto de obras que 126 a torna contemporânea, sendo ressignificada ao longo dos tempos, a literatura é marcada pela pluralidade linguística e temática, circulando em diferentes culturas e através de variados suportes textuais. Vinculada ao contexto cultural, entendemos que a literatura compreende o que se escolhe fazer dela em algum tempo e lugar, ou seja, uma produção pode tornar-se literatura, sendo lida de várias formas e em diferentes momentos. Por esse viés, as produções editoriais surdas aqui analisadas compõem o universo do que convencionamos denominar 'literatura surda'.

Assim como a literatura infantil - com terminologia usada para a distinção, por conveniência, de uma literatura universal -, que se define em termos de seu público, o adjetivo 'surda', que é atribuído ao substantivo 'literatura', viabiliza pensar que a literatura surda contempla um conjunto de textos produzidos, que circulam e são consumidos em língua de sinais, principalmente por surdos. Nesse caso, além da circulação presencial, seus registros dão-se principalmente por meio de vídeos, com suporte em DVDs e em sites da internet. A literatura surda também é composta de livros escritos em português, marcados pela cultura surda, produzidos por surdos, ou não. Nessa linha de pensamento, as obras aqui investigadas, de caráter predominantemente autobiográfico, 
em diferentes gêneros textuais, constituem o acervo bibliográfico do que se entende por literatura surda, compondo um território de produção e de consumo cultural, que constitui identidades e marca diferenças.

Karnopp (2006) utiliza a expressão 'literatura surda' para histórias que têm a língua de sinais, a questão da identidade e da cultura surda presentes na narrativa. Nessas histórias, a surdez é discursivamente produzida como presença de algo, e não como falta, representando os surdos como um grupo linguístico e cultural. Além disso, a pesquisadora propõe não falar de literatura surda como algo localizado, fechado, demarcado, muito menos de oposição à cultura ouvinte; sugere, portanto, o hibridismo cultural, em que produções surdas se fazem presentes em outras culturas, buscando um outro lugar e outras representações, uma fronteira a partir da qual se fazem presentes. Com base nisso, as obras em análise neste texto constituem a literatura surda, visto que, por meio da escrita em língua portuguesa, os autores surdos tensionam e negociam significados que transcendem territórios das comunidades surdas.

Consideramos importante acrescentar que a literatura surda "[...] está relacionada às representações produzidas por surdos, em que se produzem significados partilhados em forma de discurso [...] dentro do círculo da cultura" (MOURÃO, 201 1, p. 72). Segundo esse pesquisador surdo, a literatura surda traz histórias de comunidades surdas, constituindo um conjunto de valores e ricas heranças culturais e linguísticas. Os sujeitos reconhecem modelos e valores históricos através das várias gerações de surdos artistas plásticos, poetas, contadores de histórias, escritores, atores e outros. Assim também os surdos compartilham seus testemunhos em um espaço literário que tem o poder de influenciar o público que lê, fazendo as pessoas viver suas histórias e acreditar nas representações que elas trazem (SILVEIRA; MOURÃO, 2009).

Karnopp e Machado (2006), ao relacionarem manifestações culturais à literatura surda, afirmam que as histórias contadas de uma geração a outra repassam o orgulho de ser surdo, os valores, os feitos dos líderes surdos, as histórias de vida e as dificuldades de participação em uma sociedade que ainda exclui pela diferença linguística e cultural. Ainda de acordo com os autores, esses materiais, em geral, recontam a experiência das pessoas surdas, no que diz respeito, direta e ou indiretamente, à relação entre as pessoas surdas e ouvintes, que são narradas como relações conflituosas, benevolentes, de aceitação ou de opressão do surdo. Assim, os livros escritos por surdos compõem o acervo da literatura surda, constituindo artefatos culturais. 
Assumindo o posicionamento de Strobel (2009), a literatura surda multiplica-se em diferentes gêneros textuais, traduz experiências e memórias das várias gerações dos povos surdos, suas dificuldades e vitórias, suas atuações no cotidiano, inclusive como saem em diversas situações inesperadas, testemunhando as ações de grandes líderes e militantes surdos, e sobre a valorização de suas identidades surdas. Por esse viés, as histórias de vida narradas por surdos, traduzidas ou escritas em português, possibilitam não só o registro, mas principalmente a circulação e o consumo desses relatos de vida através de obras impressas. Como materialidade, nos livros publicados por surdos, podem-se assinalar elementos que caracterizam uma obra literária, pois são estruturados a partir de um projeto editorial, composto de conteúdo, de imagens, de paratextos, de dados catalográficos e de outros elementos. Há, nesse sentido, um processo dinâmico de produção de sentidos, pois quem lê preenche os vazios do texto segundo sua experiência de vida, propiciando a interação entre autor e leitor da obra.

Em relação à importância da literatura surda, concordamos com Rosa e Klein (201 1), pois afirmam que, para as crianças surdas, a literatura surda é um meio de referência e de aproximação com a própria cultura e o aprendi128 zado da sua primeira língua, que contribuirá na construção da sua identidade surda. Ainda conforme esses autores, a produção e a circulação da literatura surda vêm se expandindo, e um dos fatores para esse aumento é o entendimento de sua importância e a comprovação de seus efeitos quando utilizada nas escolas de surdos, para as crianças e jovens surdos, ou seja, no mundo dos surdos. Essas produções, no entanto, devem ser analisadas por pesquisadores na área da produção cultural surda, levando em conta a experiência visual dos surdos no que diz respeito ao uso e à acessibilidade linguística, bem como a qualidade temática e de utilização das imagens na obra.

No Brasil, a literatura produzida por surdos, que circula em produções editoriais, pode ser vista como meio de expressão particular e/ou de uma comunidade e como produção estética. Como possibilidade de reivindicação, a literatura surda pode constituir-se em território de contestação e de lutas, de resistência a práticas clínico-terapêuticas ou que mascaram a diferença sob o discurso da diversidade, constituindo significados sociais em comunidades surdas e outros grupos culturais. A cultura vira recurso para problemas econômicos, sociais e políticos, "[...] pois a cultura dos grupos subordinados é cada 
vez mais um meio para o reconhecimento e autoestima" (YÚDICE, 2006, p. 16).

Para exemplificar a função da literatura como recurso cultural, compartilhamos o posicionamento de Vanessa Vidal, que, ao narrar sua trajetória de vida como surda, denuncia situações de incômodo e de opressão da maioria ouvinte, assim como critica a sociedade por não reconhecer diferentes culturas, principalmente as minoritárias. Em outro excerto, também a seguir apresentado, Emanuelle Laborit, ao narrar suas experiências de vida, inclusive escolares, problematiza a não-comunicação entre ela e o mundo em que vivia, pois era excluída na escola, onde características ouvintes eram tomadas como padrões para 'normalizar' a estudante surda. Desse modo, na sequência de sua obra, a autora surda reivindica outras possibilidades de educação escolar, sobretudo com uso da língua de sinais.

Eu, como minoria em maioria ouvinte, naturalmente esquecia que não era igual a eles, submetia-me a situações que depois, bem depois, me deixavam incomodada. [...] Para os surdos, o que conta mesmo é o visual. Daí a distância abissal entre essas culturas - surdas e ouvintes! [...] A sociedade em que vivemos ainda é meio 'atrasada' quanto ao reconhecimento de culturas e valores distanciados do convencional [...] (VIDAL, 2009, p. 129).

Quase sempre ficava solitária, entediava-me em um mundo que falava em torno de mim. Às vezes, irritava-me por não compreender. Parecia-me que os outros não faziam muitos esforços para se comunicarem, fora meus pais... [...] Não gostava das professoras daquela classe chamada 'de integração', na escola. Elas queriam me fazer semelhante às crianças ouvintes. [...] Com elas, tinha o sentimento de que era preciso esconder que se é surdo, imitar os outros como pequenos robôs, mesmo quando não compreendia a metade daquilo que era dito em classe. [...] $\bigcirc$ tédio, o tédio profundo, me invade, o deserto da exclusão (LABORIT, 1994, p. 58-72).

Ao passo que as produções culturais marcam a diferença surda, esses significados construídos e negociados, ao circularem, constituem identidades, também definindo o que pode ser dito, de que maneira, quando e por quem tem autoridade para isso (FOUCAULT, 2014 ). Assim, as diferenças são exibidas, e posições de sujeito são marcadas, subjetivando leitores para o consumo da identidade produzida na obra. Ademais, a materialidade do livro 
movimenta o mercado consumidor, ainda mais se a exemplaridade for tomada como uma lição a ser seguida ou como uma leitura de autoajuda. Há, portanto, uma produção cultural do 'diferente' (neste caso, o surdo) no campo da literatura surda, que circula e é consumida pelos sujeitos.

Nessa argumentação acerca da produção e do consumo das identidades dos sujeitos 'diferentes', trazemos à tona o estudo de Silveira, Bonin e Ripoll (2010). Essas autoras afirmam que a temática da diferença adquiriu visibilidade, espalhando-se de forma tentacular no tecido social, principalmente a partir da redefinição do conceito de cultura pelos impactos de movimentos sociais de reivindicação de direitos de grupos tradicionalmente oprimidos, pelo fim de empreendimentos colonialistas, por alguns avanços da ciência que permitiram questionar a naturalidade de certas características atribuídas a uns e outros povos ou sujeitos. Assim, a importância atribuída à diferença surda dá condições para a crescente tendência de comercialização da experiência e do desejo. Tomando emprestadas as palavras das autoras,

[...] a eclosão e a visibilidade das diferenças também têm sido apropriadas pelas redes de consumo, produzindo-se, por um lado, toda uma pletora de produtos e serviços destinados aos 'diferentes', em uma estratégia de segmentação (e proliferação) de mercados, e, por outro, todo um amplo leque de textos comunicacionais abordando os grupos minoritários. [...] Nesse sentido, não se trata apenas de transformar a diferença em mercadoria, mas de potencializá-la, de torná-la espetáculo, de conferir-the certo sentido sedutor, de convertê-la em algo novo, desejável, celebrativo (SILVEIRA, BONIN; RIPOLL, 2010, p. 100).

Consideramos importante acrescentar que a literatura surda em análise neste trabalho é marcada pela narração, ou seja, os textos apresentam uma sucessão temporal, com a transformação entre uma situação inicial e final, cujos fatos estão conectados principalmente pelo relato da experiência vivida. E isso se dá através de gêneros vinculados a situações vividas, a exemplo das narrativas autobiográficas, como também por meio de gêneros ficcionais, como poemas, romances e crônicas, que enfatizam a relação entre a produção escrita e a vivência do autor da obra. Convidando Silveira (2005) para essa reflexão, podemos afirmar que a cultura é alimentada, criada, reproduzida, reforçada e, por vezes, subvertida, largamente, pelas narrativas com 
protagonistas pontuais, em circunstâncias e lugares datados (indiferentemente de sua veracidade).

Além disso, notamos que as obras aqui analisadas aproximam-se às narrativas autobiográficas e, assim, conquistam o espaço daqueles sujeitos considerados 'excluídos'. Nesse sentido, como o corpus empírico deste trabalho de pesquisa é compreendido na perspectiva do espaço autobiográfico (ARFUCH, 2010), podemos considerar que as produções dos sujeitos considerados 'diferentes' - leia-se, aqui, como de surdos -, têm-se orientado cada vez mais para a vida cotidiana das pessoas pertencentes a grupos sociais ou culturalmente desvalorizados, vinculados às lutas pelo reconhecimento. Assim, são significativos os textos assinados por pessoas importantes, extraordinárias, exemplares e valorizadas em um grupo, de testemunho das experiências cotidianas e comuns (LARROSA, 2006).

Ao observarmos que as narrativas de vida são recorrentes nas produções editoriais de surdos que circulam em português escrito, aqui entendidas como manifestações que compõem a literatura surda, não objetivamos verificar a autenticidade das manifestações autobiográficas, nem analisar que elementos das obras ficcionais estão vinculados às experiências de vida dos autores. Importa-nos, muito mais, analisar as representações surdas que são construídas nessas obras. Nessa análise, percebemos a tentativa de desconstrução de estereótipos atribuídos a surdos, de modo que se construam autorrepresentações positivas, como desenvolvemos na próxima seção deste texto.

\section{Escrita em língua portuguesa: deslocando representações}

Traduzir-se em outra língua, dialogando com outras culturas, possibilita aos surdos construírem nichos para o povo surdo requerer sua diferença e para a regulação de condutas através da cultura. A expressão em uma língua diferente da sua pode também ser compreendida como um recurso cultural, um território de reivindicações e de negociações político-pedagógicas, dando visibilidade às práticas culturais surdas. Além disso, as produções culturais surdas constituem recurso de pedagogização, em que os autores denunciam práticas escolares e ensinam como deveria ser a educação de surdos, principalmente quanto à aprendizagem de uma língua escrita. Nas obras aqui analisadas, a escrita em língua portuguesa é importante para os surdos, embora a maioria 
deles considere ser difícil aprendê-la, já que as práticas escolares também não favoreceram a qualificação desse processo de aprendizagem.

A autora Shirley Vilhalva, na obra Despertar do Silêncio, mesmo se deparando com a evolução da sua escrita, narra a sua marcante insegurança no Ensino Fundamental, "[...] por aprender a ser copista sem saber o significado da língua escrita [...]" (VILHALVA, 2004, p. 23). Discutindo o ensino de português aos surdos, tendo em vista algumas possíveis justificativas para 'o suposto fracasso escolar dos surdos', a autora surda Vanessa Vidal diz que, se houve algum atraso na escola, é porque não dispunham do apoio de intérpretes; deviam fazer cursos de Libras, para clarear e aprofundar ideias; como surda, ela "[...] não tinha uma escrita perfeita, escrevia em língua de sinais, que tem estrutura gramatical bem diferente da do português" (VIDAL, 2009, p. 48). A maioria dos autores surdos aqui investigados justificam que 'não sabem português', "[...] porque sua língua natural é a de sinais, estruturada de forma diferente. Muitos temem o português, muitos sofrem até aprender a escrever de forma razoável" (OLIVEIRA, 2005, p. 5).

Evidenciamos, assim, por parte dos autores surdos, uma crítica ao ensino escolar de português, até porque, se a linguagem escrita é difícil de ser aprendida por falantes nativos, o seu ensino aos surdos requer práticas pedagógicas bilíngues, ao contrário de práticas oralistas a que muitos surdos foram submetidos em escolas, principalmente até a década de noventa (90). Por isso, nas obras aqui analisadas, percebemos sofrimento, esforço, silenciamento e dificuldades no processo de aprendizagem escolar. Tensionamos a importância e o interesse de usar o português adequadamente na expressão escrita, pois, comumente, os autores surdos afirmam que esta não é a 'língua do surdo', que 'pensa em Libras' e geralmente se comunica em língua de sinais. Entre possíveis trechos que sinalizam isso, compartilhamos um excerto comprobatório:

É tão difícil escrever. Para fazê-lo, meu esforço tem de ser num clima de desprender energias o suficiente demasiado. Escrevo numa língua que não é a minha. Na escola, fiz todo esforço para entender o significado das palavras usando o dicionário. São palavras altas, continuam soltas. Quando se trata de pô-las no papel, de escrever meus pensamentos, eles são marcados por um silêncio profundo. Eu preciso decodificar o meu pensamento visual com palavras em 
português, que têm sinais falados. [...] Eu penso em Libras, na hora de escrever em português (SILVA, 2003, p. 30).

É importante considerar que os surdos que conseguem bem aprender a língua portuguesa tornam-se merecedores de aplausos, principalmente quando sua obra integra o mercado editorial. Assim, a partir da publicação de um livro, afirma-se a também capacidade de o surdo expressar-se em uma língua escrita, ou seja, mesmo diante das dificuldades comunicativas enfrentadas na vida familiar, escolar e social, ele é caracterizado como um exemplo, uma prova de que pode ser bem-sucedido; é como se, através da materialidade impressa do livro, tentasse mostrar que o surdo é capaz de escrever, até mesmo publicar uma obra. Essa lógica da superação fortalece, de certa forma, os discursos de normalização, visto que o 'diferente' - neste caso, o surdo, e talvez de quem talvez pouco se espera-pode, assim como os ditos 'normais', alcançar o sucesso. E isso pode ser observado na introdução de uma produção cultural surda aqui analisada:

História de luta, de sacrifícios, de vitórias. Nesta humilde autobiografia, quero deixar o meu registro de que tudo é possível quando se tem vontade, quando se acredita nas próprias forças... [...] É seguir o caminho do bem e trilhá-lo com determinação (VIDAL, 2009, p. 15).

Nas narrativas que compõem a literatura surda, o processo de produção da diferença merece um olhar analítico para o consumo cultural, ou seja, as trajetórias de vida dos sujeitos tornam-se, cada vez mais, um espetáculo a ser visto, principalmente através da produção de autorrepresentações e da exibição de condutas exemplares. Prova disso, entre outros exemplos que poderiam ser aqui compartilhados, também podemos observar no depoimento de um surdo acerca da autora Vanessa Vidal, que se consagrou um ícone que merece respeito, uma líder que orgulha outros surdos, que serve de exemplo pela luta obstinada, como vemos a seguir:

Ela sempre foi uma mulher batalhadora, as coisas podiam ser difíceis, mas ela não tinha medo, lutava para conseguir o que queria; acreditava na sua capacidade e corria atrás do seu sonho. Isso se concretizou de uma forma bem expressiva, quando quis ser miss. Ela queria e lutou para isso. Assim ela demonstra que não há coisas impossíveis ou muito difíceis para ela. [...] Eu tenho muito orgulho 
dela, porque, representando a comunidade surda, mostra com capacidade a nossa cultura, nossa língua nossa inclusão e força na sociedade de ouvintes. [...] Vanessa é líder por natureza, bonita, lutadora, humilde, determinada e capaz. Ela sempre foi muito autêntica e perseverante nas coisas que desejava. Acho que foram essas qualidades que fizeram da Vanessa essa pessoa amada e respeitada, que tem sido um orgulho para nós surdos e para nós brasileiros (MACHADO apud VIDAL, 2009, p. 171-172).

Paralelamente à tentativa de desconstruir estereótipos surdos, outras representações são constituídas nos domínios discursivos das produções editoriais surdas, inclusive através da inserção de depoimentos de outras pessoas nas obras, que legitimam a produção surda. Nesse sentido, os paratextos das obras publicadas não apenas apresentam e comentam a obra como, principalmente, transmitem a ideia de que esta lição de vida deve ser seguida por outros, como um modelo, um exemplo para outros sujeitos, principalmente surdos. Na próxima seção do texto, o olhar analítico volta-se para os paratextos das produções editoriais de surdos, buscando mostrar como possibilitam construir e consumir representações surdas.

\section{Paratextos: produção e consumo de representações}

Ao discutirem a literatura que circula de forma impressa em língua portuguesa, Silveira, Bonin e Ripoll (2010) chamam atenção para a funcionalidade dos paratextos. Estes são entendidos como conjuntos de fragmentos verbais que acompanham o texto propriamente dito, isto é, unidades amplas, como prefácios, textos da capa, ou unidades reduzidas, como título, assinatura, data, intertítulo, rubrica, comentários. Ademais, constituem invólucro sedutor para a escolha e leitura de livros, apontando para uma definição da própria obra e para a forma preferencial e adequada de lê-la. Nesse sentido, em diálogo com Foucault $(2005 ; 2014)$, discursos proliferam-se, seduzem os sujeitos, legitimam significados, constituem verdades, ainda mais contando a aprovação de quem experiencia a surdez, de quem tem autoridade para, numa relação de saber-poder, significar o sujeito surdo e sua cultura.

De modo recorrente, os paratextos das obras aqui investigadas são fortemente marcados pela glorificação, talento, determinação, sensibilidade e capacidade de expressão dos escritores surdos. A trajetória dos autores 
é, geralmente, caracterizada pela coragem, superação das dificuldades e alcance do sucesso em processos de inclusão social, descontruindo representações de sujeitos tradicionalmente excluídos. Como nessas obras são construídos modos de narrar e de representar os surdos, essas posições, assumidas em relações de saber-poder, subjetivam leitores a partir das experiências narradas e com as quais se identificam através de uma produção editorial. Essa argumentação é sustentada pelo conjunto de fragmentos selecionados, que segue apresentado a seguir:

Voo da Gaivota é um livro sobre uma mulher incomum que sensibilizou o mundo com sua vitória sobre a surdez. Num depoimento lúcido e comovente, a atriz francesa Emmanuelle Laborit expõe a sua vida, da infância à adolescência, narrando com emoção a trajetória difícil, por vezes sufocante - mas finalmente gloriosa -, em busca da realização como mulher, atriz e escritora. [...] Em $\bigcirc$ Voo da Gaivota Emmanuelle Laborit mostra por que é uma mulher especial. [...] As dificuldades, longe de a empurrarem ao fracasso, a encheram de energia, ampliaram sua vontade e a levaram ao sucesso (LABORIT, 1994, s/p.).

livro de Vera Strnadová é uma forma de mudança nos dois sentidos apontados. Ele nos leva a viver um dia a dia com os surdos, a compartilhar o seu cotidiano, a sentir na pele qual é o significado - existencial - do ser surdo. [...] $\bigcirc$ livro continua, assim, com essa nova tradição pedagógica que é a conquista do espaço das biografias daqueles sujeitos considerados como 'os outros', 'os excluídos' (SKLIAR apud STRNADOVÁ, 2000, s/p.).

Série Sentidos é voltada para a produção cultural de pessoas com necessidades especiais. A Áurea Editora e o Projeto Sentidos compartilharão com os leitores um novo universo, com verdades e certezas, daqueles que lutam com muita coragem em busca de suas realizações no processo de inclusão social. Cada autor, dentro da forma como se comunica e transita pelo mundo, vai nos ensinar por meio da ficção ou da realidade, em prosa ou poesia, o caminho da persistência e da lealdade com a vida (BADIN, 2001 , s/p.).

Esse livro pretende ressaltar que, em qualquer idade, o surdo é capaz de expressar-se. É assim que os seus sonhos, quase inatingíveis, enquanto os sonha sozinho, se tornem realidade quando os divide com o mundo (OLIVEIRA, 2005, s/p.).

Na verdade, a vida de Maria Olindina é uma lição para todos nós, é um exemplo de superação dos obstáculos e das dificuldades, de 
luta pela felicidade. [...] Podemos dizer que a história de Maria Olindina é uma verdadeira lição de vida para todos nós, pois estas páginas são um hino ao amor, são a manifestação mais pura da simplicidade, da luta pela realização dos sonhos, dos sentimentos mais sinceros que, agora, nos seus escritos, divulgados, a imortalizarão (POSSÍDIO, 2005, s/p.).

Guerreira e vencedora, hoje Brenda Costa é top model internacional. Milagre? Não: o fruto da coragem e da obstinação. [...] $E$, para além de qualquer expectativa, realizou seu sonho de princesa: ser modelo (COSTA, 2008, s/p.).

Esse livro tem objetivo de mostrar o mundo dos surdos e também as relações e conflitos possíveis que se estabelecem entre surdos e ouvintes. [...] Enfim, é útil para os que desejam conhecer como é a vida e o sentimento de uma pessoa que vive no mundo sem sons! (NEVES, 2010,s/p.).

Na leitura desses fragmentos selecionados e compartilhados anteriormente, sobressai a ideia de utilidade da obra produzida, ou seja, as produções culturais têm uma funcionalidade, que está vinculada à circulação e ao consumo das identidades e da cultura surda. Nesse caso, percebemos o desejo de narrar a experiência surda ao outro (surdo ou não), para que possa não somente conhecer os sentimentos daqueles que vivem em um mundo sem sons, mas, principalmente, aprender a agir de forma diferente, reconhecendo a capacidade do surdo, inclusive para a produção escrita em língua portuguesa. Em geral, os paratextos recomendam as obras surdas, porque mostram o caminho do sucesso por meio da superação dos obstáculos. Também são indicados para quem busca interação com surdos, rompendo barreiras linguísticas e culturais.

Ao discutir a potencialidade das narrativas, principalmente como constituidoras de imagens, de estereótipos e de representações, concordamos com Silveira (2005) ao destacar que são as narrativas pontuais - aquelas com personagens singulares, situados em um tempo e espaço - as que parecem mais contribuir para o estabelecimento de práticas culturais e de verdades, que, eventualmente, podem até prescindir da generalização cotidiana e da reiteração da moral nelas embutida. Segundo a pesquisadora, as narrativas de autoajuda, as parábolas bíblicas, as fábulas, os apólogos, as histórias patrióticas e heroicas são exemplos evidentes de uso dos casos específicos 
para convencer leitores de que estratégias de autogoverno são as mais indicadas, pois se conectam fortemente à ideia de exemplaridade, facilmente subjetivando os leitores.

Em geral, o mercado editorial está cada vez mais repleto de histórias de vida, potencializando a produção e a circulação de obras de sujeitos 'diferentes', mas bem-sucedidos. Além disso, em

[... uma sociedade que cada vez mais valoriza o espírito empreendedorista dos sujeitos, as experiências de pessoas consideradas vencedoras são exaltadas e vendidas como exemplo de que todos podem ter seu 'lugar ao sol'. Alguns sujeitos, considerados 'anormais' por diferentes motivos, como pessoas com deficiência e os surdos, quando atingem um patamar entendido como próximo da normalidade ou quando ascendem profissionalmente, são entendidos como exemplos de conduta para a sociedade, pois, 'apesar de tudo', tiveram êxito em suas metas (MIANES; MÜLLER, 2011 , $s /$ p.).

Essa receptividade por parte de leitores das obras, em diferentes campos discursivos, processa-se no circuito cultural, pois identidades e representações são constituídas quando sujeitos são interpelados pelas palavras. $\bigcirc$ poder conferido às palavras e a quem as profere se processa no circuito cultural, em que práticas discursivas constituem posições identitárias e representações que regulam o consumo. Aqui o consumo está mais relacionado a sentimentos e emoções (na forma de desejos), sendo individualista e mais preocupado em saciar vontades, que são identificadas subjetivamente. Atualmente, cada um de nós é - ou deseja ser - aquilo que consome. Logo, ao consumir uma narrativa de sucesso, que representa uma lição a ser seguida, podemos fornecer a comprovação do que somos, ou melhor, na sociedade da exibição, somos clientes e também mercadorias.

\section{Para (não) concluir}

Os significados partilhados nas produções culturais surdas que circulam em português escrito no mercado editorial brasileiro possibilitam a aproximação com outras obras publicadas por sujeitos considerados 'diferentes', vinculados a grupos minoritários/marginalizados. Isso se processa no circuito da cultura (HALL, 1997), sobretudo através da construção da identidade 
e da delimitação da diferença (quem somos e a quem pertencemos, demarcando e sustentando a diferença entre os grupos); da produção e do consumo (incorporação aos rituais e práticas cotidianas) de marcas culturais e de representações em narrativas; da regulação e da organização das condutas sociais (estabelecimento de normas e convenções que governam a vida social) através da posição privilegiada dos sujeitos autores nas obras.

É oportuno também considerar as diferentes abordagens desenvolvidas nas obras, isto é, embora algumas produções investigadas ainda evidenciem discursos clínico-terapêuticos, outras, principalmente mais atualizadas, aproximam-se de concepções antropológicas, considerando a surdez como uma diferença. E essa diferença é também marcada na expressão escrita em língua portuguesa, pois a sinalização em Libras, quando utilizada por personagens surdos em diálogos, é marcada através da letra em formato itálico, como pode ser observado no próximo excerto que compartilhamos. Além do uso da língua de sinais, da experiência visual, das lutas e da formação de comunidades surdas, outras marcas culturais surdas emergem nas obras, como o uso do sinal para identificação do(a) surdo(a), a exemplo do fragmento a seguir selecionado, em que o personagem (ouvinte) Raul parece alheio à conversa em língua 138 de sinais:

- $\bigcirc$ meu sinal é esse. (dedo polegar com movimento circular descendo desde o alto da cabeça até o ombro). É por causa do meu cabelo.

- $\bigcirc$ meu é esse. (mãos fechadas apertando bochecha). Minhas bochechas chamam atenção. Rose diz, rindo.

- Eles não têm sinais?

- Não. Você precisa 'batizá-los', Paola.

Raul não se contém e pergunta para Rose:

- $O$ que estão falando a nosso respeito? (NEVES, 2010, p. 34).

É a inserção social do surdo em domínios discursivos que constitui sua identidade e, consequentemente, a sua narrativa, datada e localizada, que poderia ser construída de outra forma. Seus discursos estão relacionados à experiência de si, tendo em vista as práticas familiares e de educação formal. Lembramos que as narrativas de surdos, de alguma forma, estão também atravessadas pelas memórias de seus familiares, que, enquanto ouvintes, contaram e ainda contam algumas histórias sobre seus filhos. Muitos pesquisadores têm se dedicado à captura dessa dinâmica nas narrativas, considerando 
contingências de produção de cada obra, isto é, onde se produzem as identidades sociais constituídas nas publicações. Isso porque

[...] o relato das histórias que vivenciamos é uma forma de trazer à tona como fomos construídos ou como estamos continuamente nos (re)construindo no próprio ato de relatar as histórias para novos/ mesmos interlocutores em outros momentos e espaços, pois quando se pergunta a alguém sobre sua identidade, uma história logo aparece [uma vez que] nossa identidade não está separada do que se passou. Na dinâmica de se relatar o que se passou, as identidades sociais surgem (MOITA LOPES, 200 1, p. 65).

Constatamos que a maioria das obras aqui analisadas são de autoria feminina, sendo que as escritoras posicionam-se em primeira pessoa, indicando a potencialidade de discursos que emergem dos surdos e legitimando esses significados. Com base nisso, observamos que, nas produções culturais surdas, há raras referências a outras culturas, tendo em vista questões de gênero e etnia, por exemplo. Ademais, importa considerar que têm crescido o número de obras publicadas por surdos no mercado editorial brasileiro, aqui considerando os resultados desta pesquisa.

Se a década de 90 é marcada por apenas uma produção cultural surda, traduzida do francês para o português, as produções, a partir do segundo milênio, avançam quantitativamente, representando 9 (nove) obras em 10 (dez) anos, isto é, praticamente um livro lançado por ano. E isso pode ser entendido como a conquista de territórios culturais, bem como a abertura do mercado editorial diante das lutas e dos movimentos das comunidades surdas, além das políticas públicas de incentivo à cultura. Paralelamente a isso, verificamos o crescimento da produção, da circulação e do consumo de obras que tematizam narrativas de sujeitos que, por algum desvio do padrão da normalidade instituída, são considerados 'diferentes'.

\section{Referências}

ARFUCH, Leonor. O espaço biográfico: dilemas da subjetividade contemporânea. Rio de Janeiro: EDUERJ, 2010.

BADIN, Celso. A juventude, o carnaval e o Rio de Janeiro. São Paulo: Áurea, 2001. 
CADEMARTORI, Lígia. O professor e a literatura: para pequenos, médios e grandes. Belo Horizonte: Autêntica, 2009.

CANCLINI, Néstor Garcia. Leitores, espectadores e internautas. Tradução Ana Golderger. São Paulo: lluminuras, 2008.

COSTA, Brenda. Bela do silêncio. Tradução Mariana Echalar. São Paulo: Martins Fontes, 2008. (Obra escrita com a colaboração de Judith Carraz).

FOUCAULT, Michel. Arqueologia do saber. Tradução de Luiz Felipe Nieta Neves. 7. ed. Rio de Janeiro: Forense Universitária, 2005.

A ordem do discurso: aula inaugural no Collège de France, pronunciada em 2 de dezembro de 1970. Tradução de Laura Fraga de Almeida Sampaio. 24. ed. São Paulo: Loyola, 2014.

HALL, Stuart. The work of representation. In: HALL, Stuart (Org.). Representation: cultural representations and signifying practices. Sage/Open University: London/Thousand Oaks/ New Delhi, 1997.

HUNT, Peter. Crítica, teoria e literatura infantil. Tradução Cid Knipel Moreira. São Paulo: Cosac Naify, 2010.

KARNOPP, Lodenir Becker. Literatura Surda. EDT: Educação Temática Digital, Campinas, v. 7, n. 2, p. 98-109, jun. 2006. (Publicação da Faculdade de Educação da Universidade Estadual de Campinas).

KARNOPP, Lodenir Becker; MACHADO, Rodrigo Nogueira. Literatura surda: ver histórias em língua sinais. In: SEMINÁRIO BRASILEIRO DE ESTUDOS CULTURAIS EM EDUCAÇÃO, 2; 2006, Canoas. Anais... Universidade Luterana do Brasil: Editora da ULBRA, 2006.

KLEIN, Madalena; LUNARDI, Márcia Lise. Surdez: um território de fronteiras. EDT: Educação Temática Digital, Campinas, v. 7, n. 2, p. 14-23, jun. 2006.

LABORIT, Emmanuelle. O voo da gaivota. Tradução Lelita de Oliveira. São Paulo: Best Seller, 1994. (Escrito com a colaboração de Marie-Thérèse Cuny).

LARROSA, Jorge. Ensaio, diário e poema como variantes da autobiografia: a propósito de um "poema de formação' de Andrés Sánchez Robayna. In: SOUZA, Elizeu Clementino de; ABRAHÃO, Maria Helena Menna Barreto (Org.). Tempos, narrativas e ficções: a invenção de si. Porto Alegre: EDIPUCRS, 2006.

LARROSA, Jorge. Tremores: escritos sobre a experiência. Tradução de Cristina Antunes e de João Wanderley Geraldi. Belo Horizonte: Autêntica, 2015. 
LOPES, Maura Corcini. Narrativas surdas: a condução das condutas dos escolares. In: XV ENDIPE: ENCONTRO NACIONAL DE DIDÁTICA E PRÁTICA DE ENSINO, 15, 2010, Belo Horizonte. Anais... Belo Horizonte: Universidade Federal de Minas Gerais, 2010.

LOPES, Maura Corcini; VEIGA-NETO, Alfredo. Marcadores culturais surdos. In: VIEIRAMACHADO, Lucyenne Matos da Costa; LOPES, Maura Corcini (Org.). Educação de surdos: políticas, língua de sinais, comunidade e cultura surda. Santa Cruz do Sul: EDUNISC, 2010.

MIANES, Felipe Leão; MÜLLER, Janete Inês. Trajetórias: diferenças narradas nas histórias de vida. In: VIII CONGRESSO INTERNACIONAL DE EDUCAÇÃO - Profissão Docente: há futuro para este ofício? 8, 201 1, São Leopoldo. Anais.... São Leopoldo: Universidade do Vale do Rio dos Sinos, 2011

MOITA LOPES, Luiz Paulo da. Práticas narrativas como espaço de construção das identidades sociais: uma abordagem socioconstrucionista. In: TELLES, Branca Ribeiro; COSTA, Cristina Lima; LOPES, Maria Dantas (Org.). Narrativa, identidade e clínica. Rio de Janeiro: IPUB-CUCA, 2001.

MORAIS, Mônica Zavacki de; LUNARDI-LAZZARIN, Márcia Lise. Pedagogia e diferença: capturas e resistências nos discursos curriculares da educação de surdos. In: THOMA, Adriana da Silva; KLEIN, Madalena (Org.). Currículo \& avaliação: a diferença surda na escola. Santa Cruz do Sul: EDUNISC, 2009.

MOURÃO, Claudio Henrique Nunes. Literatura Surda: produções culturais de surdos em língua de sinais. In: KARNOPP, Lodenir Becker; KLEIN, Madalena; LUNARDI-LAZZARIN, Márcia Lise (Org.). Cultura surda na contemporaneidade: negociações, intercorrências e provocações. Canoas: Editora da ULBRA, 2011.

NEVES, Sylvia Lia Grespan. Mãos ao vento. São Paulo: s/editora, 2010.

OLIVEIRA, Ronise. Meus sentimentos em folhas. Rio de Janeiro: Litteris/KroArt, 2005.

POSSÍDIO, Olindina Coelho. No meu silêncio ouvi e vivi. Recife: Novo Horizonte, 2005.

ROSA, Fabiano Souto; KLEIN, Madalena. $\bigcirc$ que sinalizam os professores surdos sobre a literatura surda em livros digitais. In: KARNOPP, Lodenir Becker; KLEIN, Madalena; LUNARDI-LAZZARIN, Márcia Lise (Org.). Cultura surda na contemporaneidade: negociações, intercorrências e provocações. Canoas: Editora da ULBRA, 2011.

SILVA, Edson Flávio da. O som das palavras: antologia literária. Rio de Janeiro: Litteris 2003.

SILVEIRA, Rosa Maria Hessel. Discurso, escola e cultura: breve roteiro para pensar narrativas que circundam e constituem a educação. In: SILVEIRA, Rosa Maria Hessel (Org.) Cultura, 
poder e educação: um debate sobre os Estudos Culturais em Educação. Canoas: Editora da ULBRA, 2005.

SILVEIRA, Carolina Hessel; MOURÃO, Claudio Henrique Nunes. Literatura infantil: música faz parte da cultura surda? In: SEMINÁRIO NACIONAL EDUCAÇÃO, INCLUSÃO E DIVERSIDADE, 2009, Taquara. Anais... Taquara: Faculdades Integradas de Taquara, 2009.

SILVEIRA, Rosa Maria Hessel; BONIN, lara Tatiana; RIPOLL, Daniela. Ensinando sobre a diferença na literatura para crianças: paratextos, discurso científico e discurso multicultural. Revista Brasileira de Educação, Rio de Janeiro, v. 15, n; 43, p. 98-108, jan./abr. 2010. SKLIAR, Carlos Bernardo (Org.). A surdez: um olhar sobre as diferenças. Porto Alegre: Mediação, 1998.

STRNADOVÁ, Vera. Como é ser surdo. Tradução Daniela Richter Teixeira. Rio de Janeiro: Babel, 2000.

STROBEL, Karin Lilian. As imagens do outro sobre a cultura surda. 2. ed. rev. Florianópolis: Editora da UFSC, 2009.

VIDAL, Vanessa. A verdadeira beleza: uma história de superação. Tradução Diná Souza. Fortaleza: s/editora, 2009

142 VILHALVA, Shirley. Recortes de uma vida: descobrindo o amanhã. Brasília: Gráfica e Papelaria Brasília, 2002.

VILHALVA, Shirley. O despertar do silêncio. Florianópolis: Arara Azul, 2004.

YÚDICE, George. Cultura e educação no novo entorno. In: SOMMER, Luís Henrique; BUJES, Maria Isabel Edelweiss (Org.). Educação e cultura contemporânea: articulações, provocações e transgressões em novas paisagens. Canoas: Editora da ULBRA, 2006.

Profa. Dra. Janete Inês Müller Instituto Federal Farroupilha | Campus São Vicente do Sul Coordenação Geral de Ensino Universidade Federal do Rio Grande do Sul Programa de Pós-Graduação em Educação Pesquisadora no Grupo Interinstitucional de Educação de Surdos | GIPES Pesquisadora no Grupo de Estudos em Políticas Públicas e Educação Especial | GEPPEE

E-mail | janeteim@hotmail.com 
Profa. Dra. Lodenir Becker Karnopp Universidade Federal do Rio Grande do Sul Faculdade de Educação Departamento de Estudos Especializados Programa de Pós-Graduação em Educação Líder do Grupo Interinstitucional de Pesquisa em Educação de Surdos | GIPES | DGP | $\mathrm{CNPq}$

Bolsista do Conselho Nacional de Desenvolvimento Científico e Tecnológico (CNPq), na modalidade Produtividade em Pesquisa 2 E-mail | lodenir.karnopp@ufrgs.br

Recebido 24 out. 2016 Aceito 10 jan. 2017 